\title{
Concept-applied Physiology Thinking
}

\author{
Cheng Hwee Ming
}

\begin{abstract}
Competency-based medical education has put the onus on students to comprehend, understand, and apply the competencies learned to get promoted to the next level and to ultimately graduate. I enjoy teaching my students physiological concepts by helping them put on their thinking concept-applied physiology (CAPs). My Microsoft PowerPoint may have few slides instead of jargon of every explanation already given and explained in textbooks. I lay forward concepts and questions and allow students to pause in between my lectures. This gives them ample time to wear their thinking CAP and decipher the enigma of the human body through CAP. As adult learners, we give them a platform to rationally think and make concepts for we also learn and redefine our role as facilitators and mentors and not only feed them for rote learning. I am taking you all through the Cardiorespiratory-Renal CAP ride through this article. Let us all think out of the box to stimulate the joy of learning. Keywords: Cardiovascular, Concept-applied Physiology (CAP), Physiology, Renal, Respiratory. AMEl's Current Trends in Diagnosis \& Treatment (2021): 10.5005/jp-journals-10055-0116
\end{abstract}

\section{INTRODUCTION}

\section{Once upon a Time in Kidneyland....}

A Physiology teacher wears many hats. He or she is a multitasker; a teacher, researcher, administrator, and mentor besides contributing to the life of academia as a person.

My favorite hat is the teaching hat. My colleagues generally shy away from teaching the convoluted renal physiology. So, I found myself often in Kidneyland, exploring, enjoying, and then explaining to my students the wonderful journey along the nephron. ${ }^{1}$

Renal function is integrated with cardiovascular (e.g., blood volume and pressure) and respiratory physiology (acid-base balance). In helping students to learn Physiology, I have frequently used what I called a CAP approach. I teach students to put on their thinking CAPs.

My students know me as a Minimalist PowerPoint presenter. With crowded slides that basically write out in full the explanation, students will most likely memorize them as model answers (with or without full understanding). There is less text in my slides but more concepts and principles. I sometimes get negative feedbacks from rote learners or muggers.

But isn't this ability to apply physiology concepts and knowledge what we seek to achieve in competency-based medical education?

The thinking CAP mindset will include several pathways for learning Physiology. The six words are given in the letter C (Fig. 1).

- Circular thinking-refers to the key concept of homeostasis and compensatory feedback loop.

- The Crow-refers to the larger, big picture or bird's eye view of integrated organ Physiology.

- The Cart-Horse - refers to the Cause and Effect mechanisms in Physiology, "don't put the cart before the horse."

- The Clock-includes temporal events, cycles, and rhythmic activity in Physiology. Quantitative aspects and priorities in Physiology are in the Count.

- The Chameleon — refers to adaptations to normal physiological challenges.

When we offer too quickly the answers to questions posed, we miss the chance to allow students to think through and respond. ${ }^{2}$
Department of Physiology, Faculty of Medicine, University of Malaya, Kuala Lumpur, Malaysia

Corresponding Author: Cheng Hwee Ming, Department of Physiology, Faculty of Medicine, University of Malaya, Kuala Lumpur, Malaysia email: chenghm@ummc.edu.my

How to cite this article: Ming $\mathrm{CH}$. Concept-applied Physiology Thinking. AMEl's Curr Trends Diagn Treat 2021;5(1):58-61.

Source of support: Nil

Conflict of interest: None

If we have too much to cover in the 60 minutes class, naturally we will not pause sufficiently to allow the synaptic activity among our students to continue.

Here are several examples of CAP learning I use. I encourage students to apply concepts to different scenarios in normal and pathophysiologic situations.

\section{Cardiovascular Physiology}

\section{Concept 1: Two Ventricular Pumps are arranged in Series}

It is interesting to note that quite a number of students in the class will say that the right and left cardiac pumps are arranged in parallel and this may be the visual impression in the two-dimensional textbook diagram. I emphasize that the whole cardiovascular circuit, systemic, and pulmonary is a closed loop with the two ventricles in series. So what? Is this just a functional architecture description?

So, I follow-up by saying that the serial arrangement of the ventricles in the cardiovascular loop presents a potential problem. This begins to evoke interest among the students who are now thinking "what's the potential problem?"

At this stage, I tell the students that the cardiac outputs from both the ventricles must be equalized over time. Why? I encourage the students to always ask why? why? why? (WWW). I continue asking "What would happen if the left ventricle fails and the cardiac output (CO) is less than the right ventricular CO."

While the students are thinking, I ask them to imagine the blood traffic flow as a smooth event and what would occur if a

\footnotetext{
(c) The Author(s). 2021 Open Access This article is distributed under the terms of the Creative Commons Attribution 4.0 International License (https:// creativecommons.org/licenses/by-nc/4.0/), which permits unrestricted use, distribution, and non-commercial reproduction in any medium, provided you give appropriate credit to the original author(s) and the source, provide a link to the Creative Commons license, and indicate if changes were made. The Creative Commons Public Domain Dedication waiver (http://creativecommons.org/publicdomain/zero/1.0/) applies to the data made available in this article, unless otherwise stated.
} 


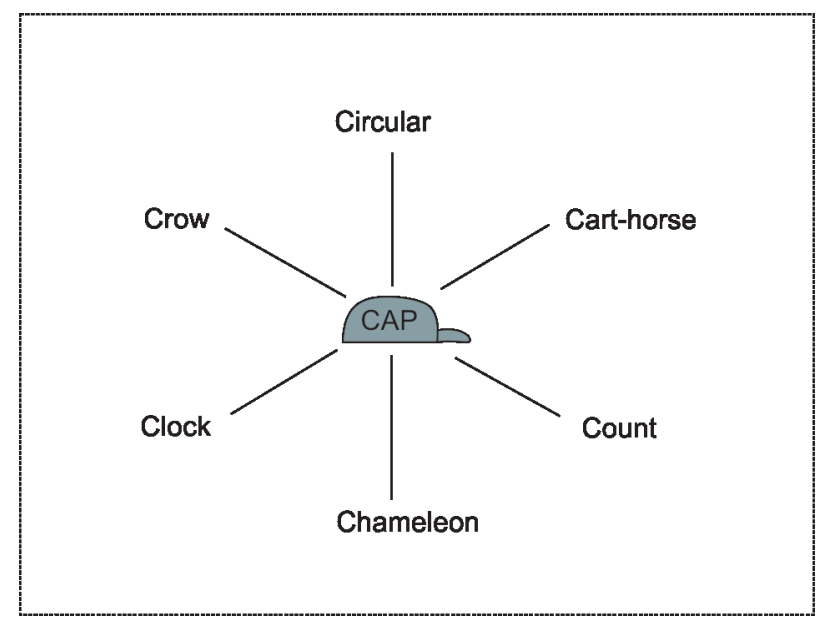

Fig. 1: Concept-applied physiology (CAP) thinking

part of the vascular highway is obstructed and a slowing of the traffic develops. Traffic congestion! I tell the students that we also use the term vascular congestion when the smooth regular blood flow becomes uneven.

So quite soon, the students can see for themselves that when the left heart is weakened, the vascular congestion will develop in the pulmonary circulation. A potential pulmonary edema will result.

Similarly, by CAP thinking, when the right ventricle fails, by the same conceptual logic, the students can easily work out that a peripheral rise in venous pressure and vascular congestion will build up and peripheral edema will occur.

And the discussion is then focused back on the point I made that both COs must be equalized over time. I ask "How do you think the COs each minute from both the ventricles in series are regulated to be equal so that no vascular congestion takes place?"

This is a good platform to introduce the myocardial intrinsic property described by Ernest Starling named Starling's law of the heart. Beat by beat, there may be small differences in the stroke volume from each ventricle, but Starling's mechanism will adjust and equalize the dual cardiac outputs over time.

\section{Cardiorespiratory Physiology}

\section{Concept 2: Hypoxia is Defined by the Cells}

This is a cell-centered perspective of hypoxia, a selfie definition!

The final purpose of the integrated cardiorespiratory function is to supply adequate oxygen or time to the cells. With this understanding, both pulmonary function and systemic blood flow must be normal to prevent cellular hypoxia.

Even when the blood is well oxygenated, if the blood flow is insufficient as in heart failure, the rate of oxygen delivered to the cells will be reduced and cells will be hypoxic. This is what is termed stagnant in circulatory hypoxia. So, the CAP thinking is that even if the partial pressure of the oxygen is normal, the hemoglobin-oxygen saturation is normal, and cellular hypoxia is still a possibility if the cardiac output is compromised.

Total blood $\mathrm{O}_{2}$ content is predominantly associated with hemoglobin that is determined by the dissolved $\mathrm{O}_{2}$ (or the partial pressure of $\mathrm{O}_{2}$ ). Changes in hemoglobin concentration do not alter the $\mathrm{PO}_{2}$ or the percentage saturation of $\mathrm{Hb}-\mathrm{O}_{2}$. It only changes the total $\mathrm{O}_{2}$ content. Any causes of decreased $\mathrm{O}_{2}$ content related to the lower concentration of or abnormal hemoglobin are named anemic hypoxia where the $\mathrm{PO}_{2}$ is still normal but the $\mathrm{O}_{2}$ content is diminished.

\section{Concept 3: Effects of $\mathrm{Hb}-\mathrm{O}_{2}$ Affinity Change is Also Cell-defined}

Students might think that a decrease in $\mathrm{Hb}^{-\mathrm{O}_{2}}$ affinity will affect the uptake of $\mathrm{O}_{2}$ in the lungs. There is redundancy in $\mathrm{Hb}-\mathrm{O}_{2}$ binding capacity, and at a relatively low $\mathrm{PO}_{2}$ of $60 \mathrm{~mm} \mathrm{Hg}$, this will already be associated with a $90 \% \mathrm{Hb}_{-} \mathrm{O}_{2}$ saturation. This indicates that the reduced $\mathrm{Hb}-\mathrm{O}_{2}$ affinity in physiologic events will not significantly affect the oxygenation in the lungs.

At the tissues, a decrease in $\mathrm{Hb}-\mathrm{O}_{2}$ is always beneficial to the cells. More oxygen is unloaded when the affinity of the hemoglobin for $\mathrm{O}_{2}$ is less.

This is the reason why by CAP thinking, the unusual increase in affinity in carboxyhemoglobin for $\mathrm{O}_{2}$ is not a beneficial compensatory effect. Rather, it worsens the carbon monoxide toxicity as the little $\mathrm{O}_{2}$ available is now bound more tightly to hemoglobin and is less easily available to the hypoxic cells.

Coincidently, or by divine design, the local tissue changes during exercise or physical activity. In skeletal muscles, all favor unloading of $\mathrm{O}_{2}$ to the more active skeletal muscle fibers. ${ }^{3}$ Local hypoxia, hypercapnia, and a warmer muscle tissue all decrease the $\mathrm{Hb}-\mathrm{O}_{2}$ affinity, so more $\mathrm{O}_{2}$ are extractable from the blood by the muscles.

\section{Cardiorenal Physiology of Blood Volume And Pressure}

\section{Concept 4: Renal Sympathetic Nerve Always Conserves Sodium}

This means that increases in renal sympathetic activity will reduce the urinary sodium excretion.

Urine volume production and urine composition are not merely excretion. The amount of urinary sodium excretion is a homeostatic response to changes in sodium balance, and total body sodium is linked to extracellular fluid (ECF) and blood volume. So, peeing is a homeostatic event.

The renal sympathetic nerve (RSN) is always activated in negative sodium balance associated with hypovolemia. The volume sensors that detect hypovolemia will trigger the baro- and volume receptor reflexes to increase sympathetic action. The renal sympathetic activity is part of the overall increase in compensatory autonomic sympathetic neural activity.

Of the many actions of RSN to conserve sodium, RSN innervates the juxtaglomerular cells that secrete renin from the afferent arteriole. Renin is also released by two other pathways involving the macula densa and the direct sensing by intrarenal baroreceptors at the afferent arteriole. Remember, Renin, and Renal Sympathetic nerve conserve sodium.

So, we can CAP think, summarize, and state that any conditions that lower blood volume and blood pressure will activate renin secretion. To be more precise, it is the effective circulating volume that determines renin secretion. This is because the blood volume can be normal but the failing heart can be pumping less cardiac output. The decreased blood pressure will then be detected by the volume sensors.

Thus, this accounts for the observed sodium and fluid retention that occurs in poor cardiac output.

Intravascular volume can decrease if there is a shift of fluid to the interstitial space. When this happens, the renin secretion can 
be stimulated. So, by CAP thinking, in nephrotic syndrome with proteinuria, the drop in the plasma oncotic pressure will lower blood volume, and renin is released.

In the endocrine hypersecretion of aldosterone, there is the retention of sodium and fluid leading to an isotonic expansion of the ECF. In this primary hyperaldosteronism, the hypervolemia reflexly inhibits renin secretion. CAP thinking tells us that normally, there is a parallel increase in renin and aldosterone blood levels. But, in this pathophysiologic endocrine disorder, low renin is, however, associated with a high aldosterone blood concentration.

\section{Renal eCF Volume Control}

\section{Concept 5: Water does not Follow Sodium at the Renal Collecting Ducts}

Students frequently say that when sodium is reabsorbed the collecting ducts, water will follow. This might sound correct. And when viewed at the intestinal epithelial cells, this isoosmotic reabsorption of water is an accurate picture of how water is transported at the epithelium. The water movement at the proximal convoluted tubule is also an isoosmotic reabsorption of water that follows sodium reabsorption that then generates a local osmotic gradient.

However, water is not isoosmotically reabsorbed at the collecting ducts. Water movement is, however, osmotically driven at the collecting ducts, when made permeable by antidiuretic hormone $(\mathrm{ADH})$, by the surrounding hyperosmotic medullary interstitium that is established by the unique renal countercurrent phenomenon.

CAP thinking will tell us that water retention that "follows" sodium reabsorption is indirect not in situ at the collecting ducts. ${ }^{4}$ As more sodium is reabsorbed at the collecting ducts as occurs in negative sodium balance with any fluid loss, the sodium retention then leads to the activation of the osmoregulation mechanism. Water is then reabsorbed more at the collecting ducts made permeable by the action of ADH released from the hypothalamusposterior pituitary osmoreceptor or ADH response system.

$\mathrm{ADH}$ and aldosterone act on the same principal cells of the collecting ducts. And, in the scenario of hypovolemia, both the levels of ADH and aldosterone are elevated in the blood. Thus, the luminal permeabilities of the principal cells are increased at the same time to both water and sodium via a stimulated number of aquaporins and sodium channels, respectively. Water is reabsorbed and driven by the dominant hyperosmotic interstitium, and sodium is reabsorbed and also conserved.

\section{Concept 6: Euvolemia from Hypovolemia Occurs Only When Sodium Balance is Restored}

It is conceptually useful for students to think step by step, the multistage of homeostatic compensation to restore both the negative water and negative sodium balance during dehydration or sweat loss. But although this is described sequentially, it is not strictly segmented along a timeline as there will be overlap in the different responses. ${ }^{5}$

The initial response will be an osmotic response whereby the fluid shifts from the intracellular fluid (ICF) space into the hyperosmotic ECF. When you think about this and the fact that sweat is always a hypotonic fluid, it is a wonderful providential coincidence of nature or divine design. If sweat is hypertonic, a hypotonic contraction of the ECF will result. Then, fluid will influx into the ICF space, and the loss of ECF volume will then be greater than the initial volume of sweat loss.
This initial transmembrane fluid shift does not normalize the ECF osmolarity. The hypertonic contraction of the ECF still remains but to a lesser degree.

The second response to the hyperosmotic ECF will be the hypothalamic osmoreceptor or ADH mechanism. The subsequent release of $A D H$ recovers more water at the renal collecting ducts. The osmoregulation normalizes the ECF osmolarity. However, it will be clear from CAP thinking that euvolemia is still not achieved as this will only occur when the negative sodium balance is also rectified. The osmoregulation at this stage converts the hypertonic contraction to an isotonic contraction of the ECF. ${ }^{6}$

In hypovolemia, the vascular volume sensing mechanisms that will conserve and restore the sodium balance will be activated. This includes an increased renal sympathetic activity as well as triggering the renin-angiotensin-aldosterone pathway. The urinary excretion of sodium is reduced. The amount of excreted sodium in urine is thus a compensatory response to ECF volume changes.

\section{Undefined Concept 7: Why Waste Urea?}

CAP thinking together with a good homeostatic curiosity will lead students to undiscovered areas in Physiology. Let us consider the solute urea, a major solute in urine. The renal handling concept tells us that organic metabolites are excreted by a combination of filtration and secretion. This contrasts with essential organic solutes like glucose and amino acids that are completely reabsorbed from the renal tubules.

Why then is around $50 \%$ of filtered urea, if it is a biochemical metabolic waste, reabsorbed at the proximal convoluted tubule? This normal passive, carrier-mediated transport by urea transporters becomes greater during a reduced glomerular filtration in renal failure, contributing to the uremia. Perhaps reabsorbed urea might have physiologic functions that are still to be defined. ${ }^{7}$

The unique urea story and journey continues when we arrive at the inner medullary collecting ducts. Here, the hormone ADH or vasopressin acts to increase not just the water permeability but also the permeability to urea. The unresolved question at the proximal tubule raises the urea head again. We tell students that this action of vasopressin allows urea recycling to occur between the collecting ducts and the loop of Henle of juxtamedullary nephrons. The maximum achievable hyperosmolarity of $1200 \mathrm{mOsm} / \mathrm{L}$ in the medullary interstitium is due to sodium chloride and also this urea reabsorbed from the collecting ducts.

CAP thinking will recall an essential principle about osmoactive solute that will contribute to an osmotic pressure. If urea remains in the impermeable collecting ducts, urea will be nonpenetrating and osmoactive, and this will oppose the water reabsorption that is promoted by vasopressin. Thus, it makes physiologic sense for vasopressin to not only add aquaporins but also urea transporters to the collecting ducts so that unopposed, effective water recovery will take place during negative water balance. Here, urea plays a contributing role to the homeostasis of water balance.

I hope this sharing on CAP thinking and learning will be helpful for both teachers and students. As educators, we can stimulate the joy of discovery when students are pushed gently to physiologically derive the expected physiologic responses, consequences, or compensations for themselves. CAP thinking should also arouse curiosity in the unclarified dimensions of Physiology.

\section{References}

1. Cheng HM. Feedback, looking back: a physiology teacher reflects. Int Med Stud Edu 2020;3:36-38. 10.51787/IMSE202000105 
2. Cheng HM, Hoe SZ. Reading physiology slowly. BLDE Univ J Health Sci 2019;4(2): 97-100. DOI: 10.4103/bjhs.bjhs_51_19.

3. Cheng HM. Homeostatic teaching: unmasking the beauty of physiology. Physiol News Br Soc Physiol 2020;119:32-34. DOI: 10.36866/ pn.119.32.

4. Cheng HM, Hoe SZ. "PhysioLego:" learning concepts, building, and applying physiology knowledge. BLDE Univ J Health Sci 2020;5(2): 97-101. DOI: 10.4103/bjhs.bjhs_9_20.
5. Cheng HM, Hoe SZ. The WRITE physiology: thinking and inking. BLDE Univ J Health Sci 2021;6(1):90-95. DOI: 10.4103/bjhs.bjhs_67_20.

6. Cheng HM, Jusof F. Defining physiology: principles, themes, concepts. Cardiovascular, respiratory and renal physiology. Springer; 2018.

7. Wang $X$, Wu L, Aouffen M, et al. Novel cardiac protective effects of urea: from shark to rat. Br J Pharmacol 1999;128(7):1477-1484. DOI: 10.1038/sj.bjp.0702944. 